\title{
LEIBNIZ Y EL DILEMA TEOLÓGICO DE LA PRESCIENCIA: LIBERTAD, DETERMINACIÓN Y CONOCIMIENTO DE LOS CONTRAFÁCTICOS ${ }^{1}$
}

\author{
María Griselda Gaiada*
}

\begin{abstract}
Resumen
En este trabajo presentaremos dos soluciones al "cuerno izquierdo" del dilema teológico sobre la presciencia: el libertarianismo molinista y el compatibilismo leibniziano. Leibniz rechazó la libertad molinista, entendida como plena indeterminación, por juzgarla incompatible con el principio de razón suficiente que opera en la elección de los hombres y es requerido para la presciencia divina. Leibniz abogó por compatibilizar la libertad con la determinación y el intelectualismo allí alojado permite ofrecer una elucidación del conocimiento divino de los condicionales contrafácticos.
\end{abstract}

Palabras clave: Presciencia; libertad; principio de razón suficiente.

\begin{abstract}
In this paper we will offer two answers to the "left horn" of the theological dilemma about foreknowledge: the Molinist libertarianism and the Leibnizian compatibilism. Leibniz rejected the Molinist freedom, which was understood as absolute indetermination, because it was judged by him as incompatible with the Principle of Sufficient Reason that operates in human choice and it is required for divine foreknowledge. Leibniz argued for making freedom compatible with determination, and the supposed intellectualism allows for an elucidation on the divine knowledge of counterfactual conditionals.
\end{abstract}

Keywords: Foreknowledge; freedom; Principle of Sufficient Reason.

${ }^{1}$ Este trabajo fue realizado bajo la dirección del Dr. Oscar M. Esquisabel. * Licenciatura en Filosofía y Doctorado en Filosofía en etapa final en Universidad Nacional de La Plata (UNLP). Correo electrónico: magriseldag@hotmail.com. 
El objetivo de este artículo es desarrollar la perspectiva leibniziana acerca de la presciencia divina, partiendo del llamado "dilema teológico." Como veremos, cada uno de los cuernos del dilema representa dos posiciones antagónicas: por un lado, el cuerno izquierdo expresa el incompatibilismo, esto es, la tesis de que la determinación que reclamaría la presciencia divina es incompatible con las acciones libres; por otro lado, el cuerno derecho niega la presciencia y con ello la omnisciencia divina, lo que desembocaría en la destitución de Dios por la negación de uno de sus atributos esenciales. A grandes rasgos, la solución de este dilema se encaró de dos maneras: (1) el compatibilismo, a saber, la tesis que compatibiliza la determinación con la libertad y (2) el libertarianismo, a saber, la tesis que afirma que el compatibilismo es falso, es decir, que la libertad no es reconciliable con la determinación, por cuanto ser "causa libre" implica ser indiferente a cualquier determinación, es decir que, aún dados todos los requisitos para actuar, es posible suspender la acción. Entre los partidarios de estas dos corrientes, encontramos que Molina se embanderó con el libertarianismo y que Leibniz le respondió adhiriendo a una posición compatibilista. Luego de presentar ambas "soluciones," nos centraremos en la "teoría leibniziana del conocimiento divino de los condicionales contrafácticos" - en el caso de que hubiera tal cosa -, con vistas a ofrecer una interpretación acerca de cómo conocería Dios los futuros contingentes. ${ }^{2}$

\section{El dilema teológico}

Este dilema, cuya validez formal es evidente, ha sido presentado como sigue: hay presciencia divina o no hay presciencia divina (premisa disyuntiva 1); si hay presciencia, entonces no hay libertad (premisa condicional 2); si no hay

\footnotetext{
2 Antes de comenzar con el desarrollo, cabe aclarar que todas las citas que aquí figuran han sido traducción de la autora.
} 
presciencia, entonces Dios no es omnisciente (premisa condicional 3), de lo que se concluye que la libertad o bien Dios deben ser abandonados (conclusión disyuntiva). A saber:

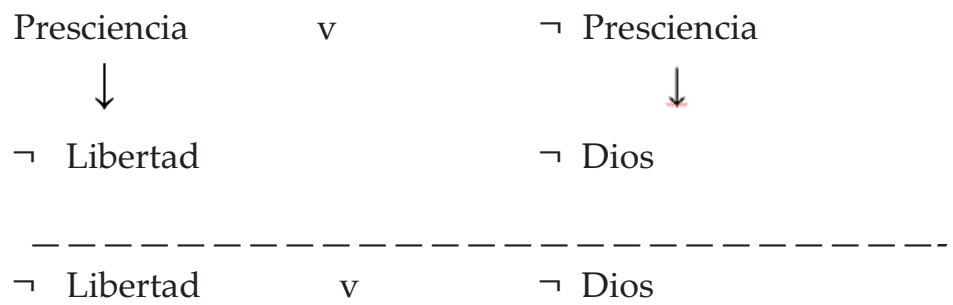

A grandes rasgos, hubo dos formas de atacar este dilema: por un lado, cuestionando la premisa disyuntiva, es decir, "escapando entre los cuernos del dilema"; por otro lado, atacando alguna de las premisas condicionales del dilema, esto es, "tomándolo por uno de sus cuernos" (Angelelli, 2008, p. 43). Dado que el cuerno derecho no puede ser aceptado por los partidarios de la presciencia, las posiciones que veremos optaron por atacar la verdad del cuerno izquierdo del dilema ("Si hay presciencia, entonces no hay libertad"), el cual tiene su fundamento en el principio de bivalencia. En otras palabras, si por " $\mathrm{p}$ " se entiende la formulación de un hecho futuro contingente, la presciencia divina cabalga sobre la idea de que Dios sabe si " $\mathrm{p}$ " ha de tener lugar o no en el mundo actual. Pero esto amerita algunas explicaciones.

La presciencia y el principio de bivalencia. - El principio de bivalencia (PB) es una ley lógica ( $\mathrm{p} v \neg \mathrm{p}$ ) $\mathrm{y}$, como tal, necesariamente verdadera. Supongamos, por ejemplo, la disyunción "Judas cometerá delación o no cometerá delación." Sabemos que la disyunción entera es lógicamente necesaria, pero, dado que el PB no puede ser "dividido," no estamos en posición de afirmar cuál de los disyuntivos es verdadero. Entonces, si alguien pudiera determinar cuál de los disyuntivos es verdadero (V. g. Dios), parecería que la acción allí simbolizada devendría necesariamente verdadera. 
Ahora bien, la no división del PB ha sido interpretada generalmente de dos maneras (sin considerar la posibilidad de un tercer valor de verdad). Por un lado, hay un sentido bivalenteepistémico, según el cual la disyunción no puede ser dividida, porque no sabemos qué disyuntivo es verdadero, aunque asumimos que uno de ellos debe serlo. Por otro lado, siguiendo una interpretación modal, afirmamos que la disyunción es necesariamente verdadera, si bien ni " $\mathrm{p}$ " ni " $\neg \mathrm{p}$ " son necesariamente verdaderas. El sentido epistémico, por entroncar con nuestras limitaciones cognitivas, se muestra insuficiente para dar cuenta del conocimiento divino de los hechos futuros, por cuanto, independientemente de nuestro conocimiento, la sentencia "Judas cometerá delación" tiene un valor de verdad accesible a Dios, si bien "clausurado" para nosotros (Angelelli, 2008, p. 45).

Por su parte, el sentido modal entiende al PB como una verdad lógica y, por tanto, necesaria, ${ }^{3}$ pero, dado que los disyuntivos no son lógicamente necesarios por sí mismos, cabe enfatizar que alguno de ellos es contingentemente verdadero. Así pues, aunque Dios pueda determinar cuál de los disyuntivos se corresponderá con la acción a emplazarse en el mundo, el acto en cuestión no queda necesitado por ello, ya que se trata de una verdad contingente. Leibniz adhirió a este sentido modal, es decir, aceptó sin restricciones el PB que opera en la presciencia, pero se

\footnotetext{
${ }^{3}$ Angelelli, por su parte, rechaza tanto el sentido epistémico como el sentido modal y asume una posición constructivista que se abstiene de aceptar la validez del PB cuando lo que está bajo consideración son los futuros contingentes. En ausencia de una prueba para dar razón de " $\mathrm{p} v \neg \mathrm{p}$," sólo tenemos buenas razones para asertar " $\neg(\mathrm{p} v \neg \mathrm{p})$ ” - dada la existencia de un algoritmo que la hace decidible-. La restricción del PB bajo esta interpretación constructivista tendría el beneficio de atacar con éxito el cuerno izquierdo del dilema. Más aún, la teoría lógica no resulta obliterada por tal restricción, puesto que toda la silogística categórica aristotélica permanece incólume y nada evitaría reinstalar el PB al apartarse de la consideración de los futuros contingentes (Angelelli, 2008, p. 45-47).
} 
abocó a justificar la contingencia de los eventos futuros que Dios conoce. En general, la estrategia de justificación de los futuros contingentes siguió un doble camino: mediante el principio de contradicción, en tanto la negación de una verdad contingente es lógicamente posible (es dable pensar que se ofrece a la visión divina un mundo posible donde Judas no ha de entregar a Cristo), y mediante el principio de razón suficiente, en la medida en que la demostración de una verdad contingente requiere de pruebas al infinito, dando razones para razones sin concluir jamás en una identidad. En este sentido, cabe pensar que Dios puede resolver los predicados que pertenecen a cierto individuo y ver, en principio, el fin de las resoluciones continuadas.

Por su lado, Luis de Molina ofreció una singular interpretación modal de la presciencia. Argumentó que si "Dios conoce que Judas cometerá delación" implica necesariamente que "Judas cometerá delación" (necesidad de dicto), pero no implica que "sea necesario que Judas cometerá delación" (necesidad de re) -incluso si el antecedente fuera necesariamente verdadero-. Puede verse que la finalidad de la negación de la necesidad de re es rechazar que haya alguna necesidad inherente a la agencia moral, dado que, como veremos, la posición libertaria de Molina se asienta en la idea de que las acciones humanas permanecen totalmente indeterminadas.

\subsection{Contra el cuerno izquierdo: el libertarianismo}

Además de la cuestión modal, Molina procuró atacar el cuerno izquierdo del dilema teológico mediante dos vías: por un lado, el argumento del doble por qué $e^{4}$ y por otro, apostando a una

\footnotetext{
${ }^{4} \mathrm{El}$ argumento del doble por qué también fue utilizado por Leibniz, si bien de un modo que resultara compatible con la determinación. Por ejemplo, en De libertate, fato, gratia Dei, Leibniz escribió: "Nam si Deus infallibiliter praescivit Petrum esse abnegaturum, infallibile id erat Petrum esse abnegaturum.
} 
solución proveniente de su noción de Scientia Media. El argumento del doble por qué afirma que "Judas peca no porque Dios tiene presciencia de ello," sino que "Dios tiene presciencia del pecado de Judas, porque Judas peca." El conocimiento de Dios no fabrica necesidad de re, por el contrario, las acciones del hombre son libres y, por ende, no pesa sobre ellas ninguna determinación, a no ser la que brota de la propia voluntad del agente.

Así pues, la libertad molinista se centra en la diferencia entre causa natural y causa libre. Mientras las causas naturales están enteramente determinadas cuando están dados todos los requisitos para la acción, las causas libres son naturalmente indiferentes en sus acciones, es decir, que aún cuando estén supuestos todos los requisitos para actuar, la acción puede producirse o no (Greenberg, 2005, p. 219). En este sentido, la voluntad es indiferente a determinaciones externas, incluso a las provenientes del entendimiento, o más bien tiene un poder autodeterminante para iniciar las acciones por su cuenta (voluntariedad intrínseca). De aquí se sigue, pues, la impredicibilidad de las acciones humanas. En otras palabras, las acciones

Quodsi infallibile, utique erat necessarium. Ad hoc respondetur, infallibilitatem non facere necessitatem. Petrum enim non fuisse abnegaturum, quia Deus praesciverat, sed Deum praescivisse quia Petrus erat abnegaturus. Et cum omissa etiam praescientia Dei futurorum contingentium in se sit determinata veritas, adeoque ab aeterno verum fuerit Petrum esse abnegaturum; utique praescientiam debere veritatem relinquere qualis erat nempe contingentem." En efecto, si Dios ha previsto de modo infalible que Pedro ha de negar, era infalible que Pedro habría de negar. Si ello era infalible, era ciertamente necesario. Se responde a esto que la infalibilidad no fabrica necesidad. Pedro no habría pues de negar, porque Dios lo había previsto, sino que Dios lo había previsto, porque Pedro habría de negar. E incluso con omisión de la presciencia de Dios de los futuros contingentes, la verdad está determinada en sí, y de tal modo que habrá sido verdad desde siempre que Pedro habría de negar; en efecto, la presciencia debe dejar a la verdad tal cual era, esto es, contingente" (A VI 4, p. 1597). 
implicadas por la legalidad física son en principio predecibles por una mente finita en disposición de una ciencia natural bien fundamentada; mientras que ninguna acción, entendida como "causa libre," podría ser predecible por criatura alguna, por más completo que fuera su conocimiento sobre el mundo (Davidson, 1998, p. 388-390).

Ahora bien, si no hay determinación, la pregunta es ¿cómo Dios puede conocer lo que una criatura elegiría bajo ciertas circunstancias? La respuesta molinista tomó la forma de un cierto tipo de conocimiento que se llamó "ciencia media," el cual permitiría a Dios conocer prevolitivamente lo que una criatura racional podría elegir libremente bajo cualquier circunstancia en la que fuera creada ${ }^{5}$. El objeto de la ciencia media son los eventos que en el léxico escolástico recibieron el nombre de "futurubilia," es decir, lo que comúnmente conocemos como "futuros contingentes condicionales." Así pues, quod Deus vidit futurum, non potest non esse futurum (lo que Dios ha visto como futuro, no puede ser sino el futuro). Pese a ello, este conocimiento divino no encierra ninguna clase de determinación, puesto que las circunstancias que anteceden a la libre elección - las que estarían especificadas en el antecedente del condicional - no tienen poder determinante

\footnotetext{
${ }^{5}$ Como señala Murray, el término "medio" fue utilizado por los jesuitas para introducir una tercera categoría entre los dos tipos de conocimiento divino que reconocieron los dominicos. A saber: "para los dominicos, todo conocimiento divino era o bien «natural», o bien «libre». El primero consiste en proposiciones que son necesarias y cuyo valor de verdad es independiente de la voluntad divina. El segundo consiste en proposiciones que son contingentes y cuyo valor de verdad depende de la voluntad divina [por concurrencia de Dios a los actos de las criaturas]. Molina sostuvo que los condicionales subjuntivos de la libertad humana no podían caer bajo tales categorías en tanto, mientras fueran contingentes, eran independientes de la voluntad divina. Como resultado, introdujeron la nueva categoría de ciencia "media» que consiste en tales proposiciones." Los corchetes son nuestros (Murray, 1995, p. 79).
} 
sobre la voluntad. La voluntariedad intrínseca que los molinistas concedieron a la voluntad humana resiste todo determinismo ejercido desde "afuera" y proclama que, aún estando dados todos los requisitos para la acción, la voluntad puede resolverse por sí misma absteniéndose del acto "esperable" en tales circunstancias. Como resultado, no hay nada en las circunstancias de la elección que pudiera guiar a Dios para saber si la criatura realizará una acción u otra. Y esto es así porque, de existir condiciones antecedentes suficientes para determinar la acción de la criatura, ello bastaría para destruir la libertad que es incompatible con la determinación. En consecuencia, "no podría haber ningún antecedente de la acción libre humana que fuera suficiente para alguien, incluso para un ser omnisciente, en vista de predecir lo que una criatura haría ${ }^{6 \prime}$ (Murray, 1995, p. 82).

No obstante, aún en ausencia de circunstancias antecedentes determinantes, Dios conoce los futuros contingentes de toda criatura: la ciencia media toma por objeto las verdades contingentes prevolitivas $\mathrm{y}$, de algún modo que no resulta muy claro, puede ver cómo la voluntad de la criatura ha de resolverse en el futuro por sí misma. Sin embargo, si fuéramos más allá de esto y quisiéramos saber exactamente qué es lo que permite a Dios preconocer las acciones futuras o el modo en que esta ciencia media es administrada en cada caso, Molina contestaría: "nada, y nada podría hacer esta determinación, dado el hecho de que la libertad requiere el tipo de indiferencia que no tiene en cuenta tal determinación" 7 .

\footnotetext{
6 "As a result, there could be no antecedents to a free human action which were sufficient for anyone, even an omniscient being, to predict what the creature would do."

7 "Nothing, and nothing could make this determination given the fact that freedom requires the sort of indifference that does not allow for such 'determination'."
} 
Lo cierto es que Leibniz advirtió este problema. Su objeción hizo blanco en el fundamento de la ciencia media, porque, tal como ha sido presentada, esta ciencia carecería de todo fundamento racional sin poder explicar la futurización divina de las acciones contingentes, ameritando así la destitución del lugar de ciencia. Leibniz ejemplificó la dificultad con el curso de la acción de David, desviado de entrar en Kegila tras consultar a Dios sobre cómo le iría allí, pues ¿qué fundamento pudo tener Dios para ver lo que harían los kegilitas? (GP VI, p. 125) Así pues, consideró que todo acto libre siempre responde a razones y que es gracias al principio de razón suficiente, que recorre el intelecto de Dios cuando futuriza las acciones de los hombres, que cabe hablar de una ciencia media. En consecuencia, el rechazo leibniziano a la libertad como indeterminación brota justamente de la violación del principio de razón suficiente.

En suma, la pretendida resolución molinista del cuerno izquierdo del dilema por vía de la ciencia media resultó insuficiente. La ciencia media de Molina, al carecer de un fundamento racional para tomar por objeto lo futurible, constituyó más bien un recurso nominal que pasó por alto la verdadera dificultad del dilema teológico y, en rigor, "no tuvo ningún impacto sobre el cuerno izquierdo del dilema" (Angelelli, 2008, p. 50).

\subsection{Contra el cuerno izquierdo: el compatibilismo}

Cabe preguntarse entonces cómo encaró Leibniz dicho problema. En primer lugar, recuperó el intento molinista de atacar el cuerno izquierdo del dilema, aunque se diferenció del libertarianismo procediendo a una redefinición material de los términos sustanciales que componen el condicional. Si bien asimiló el concepto de "ciencia media," entendió que la libertad exige una nueva definición que no puede homologarse a la pura indiferencia. Su respuesta fue, pues, compatibilista: buscó que la libertad fuera compatible con una ciencia media bien fundamentada (principio de razón suficiente), sin caer en la consecuencia indeseable del 
dilema, esto es, en la necesidad lógica de las acciones. Aunque Dios pudiera determinar el valor de verdad de los disyuntivos que conforman el principio de bivalencia, recurriendo a las condiciones antecedentes que inclinan al agente, este conocimiento no afectaría en nada la contingencia requerida para la libre acción.

A juicio de Leibniz, la presciencia trabaja con el principio de razón suficiente, el cual no implica la necesidad lógica de las acciones, sino tan sólo una forma de determinismo que en un principio Leibniz llamó "necesidad hipotética." La argumentación leibniziana siguió, pues, dos pasos: en primer lugar, una crítica a la libertad molinista con miras a ofrecer su propia definición de libertad; en segundo lugar, una fundamentación de la ciencia media que hiciera posible el conocimiento de los condicionales contrafácticos.

Refutación de la libertad molinista. - El núcleo de la crítica leibniziana a la indiferencia de equilibrio radica en que una libertad así entendida resulta una facultad irracional que atenta contra el alma de la libertad (actuar con inteligencia). Lo sustancial de esta argumentación ha perdurado en el pensamiento de Leibniz a través de las décadas ${ }^{8}$. Podemos afirmar, entonces, que el corazón

\footnotetext{
${ }^{8}$ Según Lagerlund \& Myrdal, el rechazo de la indiferencia de equilibrio ha sido "uno de los mayores hilos del pensamiento temprano y tardío de Leibniz acerca de la libertad." Ambos creen que este aspecto no ha recibido la atención debida de parte de la literatura que trata sobre la contingencia y la necesidad. Sostienen: "muchos intérpretes advierten que Leibniz está bajo la presión de su tesis de la inhesión conceptual algo que el mismo Leibniz admite-, pero fallan en mencionar que su concepción de la libertad está también determinada por una perspectiva resultante de la libre acción, donde la crítica a la libertad de indiferencia juega un rol importante. Como resultado, algunos comentadores concluyen que Leibniz tuvo problemas para proveer una perspectiva adecuada de la libertad, sin anoticiarse de que Leibniz explícitamente rechazó los mismos estándares que ellos consideran necesarios para una perspectiva adecuada, esto es, alguna clase de libertad de indiferencia" (Lagerlund; Myrdal, 2006/2007, p. 171).
} 
de la crítica a la posición libertaria reside en el intelectualismo de Leibniz, es decir, en la tesis de que la voluntad no puede desconocer las razones que le ofrece el entendimiento y, en consecuencia, no puede haber acciones indiferentes a tal determinación. Las tesis principales de la posición de Leibniz al respecto podrían ser historizadas así:

(1) La libertad molinista socava la cadena causal: Esta tesis fue sostenida tempranamente en Von der Allmacht und Allwissenheit Gottes und der Freiheit des Menschen (1670-1671?). Si el libre arbitrio fuera la capacidad de una criatura racional de querer esto o aquello independientemente de causa alguna, se desplomaría la cadena adamantina de causas sucesivas ${ }^{9}$ y se removería a Dios de su propia naturaleza -causa primera y última de todas las cosas - (A VI 1, p. 545). Volviendo al ejemplo de David y Queilá, Leibniz nos alerta del poco éxito que podría haber tenido Dios en su visión, si la voluntad de los queilenses no estuviera vinculada a alguna causa. Dios no podría saber hacia dónde se inclinaría la balanza de esas voluntades, más aún cuando ni siquiera se trata de acciones futuras a producirse en este mundo, sino de acciones que habrían podido suceder (o condicionales contrafácticos) de ser otras las circunstancias que les sirvieran de escenario. Irónicamente, ataca el "ingenio sin par" de Fonseca y Molina, quienes habrían creado una ciencia de gran sutileza, la Scientia

\footnotetext{
${ }^{9}$ En sintonía con lo que parece desprenderse de este escrito, Carlin sostiene que sólo la necesidad metafísica es incompatible con la libre elección, no así la necesidad causal. Así como en el mundo hay determinismo físico, también lo hay en las facultades involucradas en la elección. A su juicio, la consistencia lógica del sistema entero exigió a Leibniz tomar una línea determinista a nivel metafísico, en tanto se ha comprometido con la idea de un mundo físico que es igualmente determinista. El determinismo físico, que hace que un cuerpo pase de un estado a otro según las leyes naturales (causalidad eficiente), tiene su correlato en un determinismo metafísico, que hace que el alma pase de una percepción a otra y, a su vez, la voluntad de una inclinación a otra según reglas prácticas o fuerzas apetitivas (casualidad final) (Carlin, 2004, p. 365-379).
} 
Media, que no hace sino clausurar cualquier dilucidación posible de los cursos de acción del hombre. Creyendo que iban al auxilio de los atributos de Dios y de la libertad del hombre, sabotearon la presciencia que resultó un conocimiento inexplicable y encerraron la libertad dentro de un cofre sellado a las claves de la visión divina.

(2) La libertad molinista es inconsistente con el principio de razón suficiente: Esta tesis fue defendida en De indifferentia aequilibrii (1677?), donde Leibniz comparó la voluntad divina con una balanza en equilibrio. Si Dios quisiera que la balanza se inclinara hacia un lado, sin ninguna razón para ello, decretaría algo inconsistente. A saber:

Y tal es la ficción de aquellos que introducen la indiferencia de equilibrio en la voluntad, como si Dios quisiera al mismo tiempo dos cosas: una voluntad perfectamente indiferente hacia uno de los dos lados y no obstante también determinante de ello ${ }^{10}$ (A VI 4, p. 1355).

Dado que, a juicio de Leibniz, la voluntad estaría determinada siempre por las razones del entendimiento (principio de razón), elegir de manera indiferente es contradictorio con la determinación que la mueve en cierta dirección. En ausencia de un rol intrínsecamente funcional, la voluntad carece de poder para determinarse a sí misma y espera que el entendimiento cubra esa vacancia. Entonces, la indiferencia de equilibrio fallaría por desconocer lo que hace el entendimiento.

(3) La libertad molinista es una imposibilidad lógica: Esta tesis no es más que un corolario de la anterior. En Du franc arbitre (1678-1680/81?), Leibniz sostuvo que es imposible actuar sin tener

\footnotetext{
10 "Et talis est fictio eorum, qui introducant indifferentiam aequilibrii in voluntate, quasi Deus simul duo voluerit voluntatem perfecte ad utrumque indifferentem, et tamen etiam se determinantem".
} 
razones para ello, de donde se sigue que la libertad de indiferencia es una imposibilidad lógica desde el punto de vista del principio de razón (A VI 4, p. 1408). En esta línea, Murray afirma que atribuir a la voluntad una capacidad arbitraria es "lógicamente imposible" y que, "si fuera incluso lógicamente posible, es de hecho falso dada la verdad del principio de razón suficiente ${ }^{11 "}$ (Murray, 1995, p. 83).

(4) La libertad molinista es incompatible con la razón formal de la libertad: Esta tesis fue formulada en De libertate et gracia (16801684?). La razón formal de la libertad no puede ser la indiferencia absoluta, porque no tiene nada en común con la naturaleza de la mente (A VI 4, p. 1455). Conforme a este intelectualismo, no sólo la indiferencia es extranjera a los espíritus, sino que la libertad debe hundir sus raíces en un esquema formal racional. Por consiguiente, las determinaciones de la voluntad procederían de la mente y la libertad de la criatura consistiría en la "potencia de desviar la mente hacia otros pensamientos ${ }^{12 "}$. Esto ha llevado a autores como Greenberg a afirmar que "la concepción de la

11 "Leibniz argues in different places, first, that this view is logically impossible and second, that even if it were logically possible it is in fact false given the truth of the Principle of Sufficient Reason".

${ }^{12}$ De libertate a necessitate in eligendo (1680-84): "At quia [creatura] infinitos actus simul elicere non potest; ideo libertas ejus consistit in potentia avertendi mentem ad alias cogitationes. Sed cur avertit? ob molestiam aliquam in ipso cogitando, et voluptatem in alio cogitando. Ergone mens determinatur a molestia et voluptate? Non utique. Etsi semper inclinet in partem ubi majus bonum impraesens apparet, inclinat tamen libere, ita ut posset aliud eligere; quia sponte agit." / "Por el contrario, dado que la criatura no puede elegir infinitos actos simultáneamente, se sigue que la libertad de ellas consiste en la potencia de desviar la mente hacia otros pensamientos. Pero ¿por qué se desvía? A causa de alguna molestia en el mismo pensamiento y del placer puesto en otro pensamiento. Ergo ¿la mente está determinada por la molestia y el placer? No, en absoluto. Aún cuando siempre se incline hacia el lugar donde parece estar el mayor bien, se inclina no obstante libremente, de modo tal que podría elegir otra cosa, porque actúa espontáneamente" (A VI 4, p. 1455). 
mente de Leibniz parece robar a los seres humanos el poder de iniciar sus propias acciones, y su reducción metafísica de las elecciones a la suma de varias tendencias en la mente parece transformar la mente en un mecanismo ${ }^{13 "}$ (Greenberg, 2005, p. 228).

(5) La libertad molinista deja sin fundamento a la presciencia: Todas las afirmaciones anteriores conducen a esta tesis. Dado que la presciencia de Dios se vale del principio de razón suficiente, el tratamiento molinista de la libertad ha dejado a Dios en disposición de una "ciencia" que carece de apoyo racional. Es decir, no puede explicarse en qué sentido las acciones humanas serían predecibles para Dios, rebajándolo así al peldaño de una mente finita, incapaz en sentido estricto de poder predecir las acciones libres.

La libertad leibniziana. - Tras el rechazo de plano de la indiferencia de equilibrio, cabe preguntarse cómo Leibniz entendió la libertad. Él mismo ha dicho que siguió a las "escuelas de teología" en su definición (GP VI, p. 288). Es decir, la libertad consiste en inteligencia, espontaneidad y contingencia. La inteligencia "es como el alma de la libertad;" la espontaneidad supone que el principio de la acción reside en el agente y la contingencia radica en la ausencia de necesidad lógica en las acciones (GP VI, p. 288).

En cuanto a la inteligencia, cabe decir que un acto libre es aquel que se sigue de un conocimiento distinto del objeto de deliberación, es decir, de una examinación racional que mueve al agente a elegir lo mejor. Este conocimiento distinto recoge el sentido clásico del "autogobierno" (o autolegislación) y se opone al pensamiento confuso (GP VI, p. 288) que pesa sobre los motivos heterónomos que reducen la libertad del agente (esclavage des passions). La libertad es, pues, sinónimo de actuar con inteligencia.

En segundo lugar, la espontaneidad supone que el agente es enteramente dueño de sus actos, es decir, que puede responder

\footnotetext{
13 "After all, Leibniz's conception of the mind seems to rob human beings of the power to initiate their own actions, and his metaphysical reduction of choices to the sum of various tendencies in the mind seems to transform the mind into a mechanism."
} 
por ellos, porque no ha sido obligado ni forzado a actuar de cierta manera por un tercero. A decir verdad, dada su teoría de la sustancia (mónadas sin ventanas), Leibniz concedió la tesis aristotélica de que "una parte de los principios de nuestras acciones estaban fuera de nosotros" (GP VI, p. 289) como una manera inexacta de hablar a fin de hacerse entender en el ámbito de la filosofía práctica, pero, en un sentido metafísico, "nuestra espontaneidad no sufre ninguna excepción, y las cosas exteriores no tienen ninguna influencia física sobre nosotros, hablando con rigor filosófico ${ }^{14 \prime}$ (GP VI, p. 289). En suma, la espontaneidad representa nuestro imperio sobre las acciones propias.

Por último, diremos unas pocas palabras sobre la contingencia. Una acción libre es contingente porque no está afectada por la necesidad lógica, es decir, es posible que suceda lo contrario. En el ámbito de la agencia moral, la contingencia satisface la condición negativa de la ausencia de necesidad lógica, pero Leibniz deja escaso margen para un sentido más pleno de la misma -lo que tendría "tufillo" a libertarianismo-. No hay que olvidar que el determinismo leibniziano es marcado y que en el ámbito moral es identificado en esta época con el nombre de "necesidad moral." Así pues, la única necesidad que opera en la acción es la necesidad moral, a saber, la necesidad propia de la obligación que brota de la razón. No obstante, las razones que inclinan a la voluntad nunca son plenas o necesitantes ${ }^{15}$, lo que

${ }^{14}$ «Il est vray que les impressions des choses exterieures nous detournent souvent de nostre chemin, et qu'on a cru communement qu'au moins à cet egard, une partie de principes de nos actions étoit hors de nous; et j'avoue qu'on est obligé de parler ainsi, en s'accommodant au langage populaire, ce qu'on peut faire dans un certain sens, sans blesser la verité : mais quand il s'agit de expliquer exactement, je maintiens que nostre spontaneité ne souffre point d'exception, et que les choses exterieures $n^{\prime}$ ont point $d^{\prime}$ influence physique sur nous, à parler dans la rigueur philosophique.»

${ }^{15}$ Ya en 1677 Leibniz había insistido con esta idea. Ver su argumentación en Conversatio cum Domino Episcopo Stenonio de Libertate (A VI 4, p. 1383). 
para Leibniz alcanza para salvaguardar el sentido de la contingencia.

Como puede verse, es clara la posición intelectualista de Leibniz o, como dice Grua, "su posición muy personal se sitúa a la vanguardia de la ontología de la esencia anterior a la existencia; por lo tanto en todo espíritu la inteligencia domina a la voluntad $^{16 "}$ (Grua, 1953, p. 131). Para Leibniz, actuar de acuerdo al juicio constituye "la esencia de la voluntad" $y$, aunque en los hombres pueda haber "un largo trayecto del espíritu al corazón" (GP VI, p. 301), quien sigue la obligación moral se eleva a la posición de sabio. Queda claro entonces que en cualquier caso la voluntad está determinada, en Dios lo está siempre por el entendimiento, en las criaturas a veces también por las pasiones, pero lo cierto es que la balanza nunca deja de estar inclinada. Como veremos, las deliberaciones que anteceden a la acción de las criaturas tendrán su rol a propósito de la presciencia. Es preciso entonces dar cuenta de cómo contribuiría esta definición de la libertad a establecer una "teoría del conocimiento divino de los condicionales contrafácticos."

\section{Teoría del conocimiento divino de los condicionales contrafácticos.}

En los pasajes citados, hemos visto que la voluntad leibniziana carece de una voluntariedad intrínseca y, en todo caso, cabría hablar de una voluntariedad extrínseca, por cuanto la facultad que "da origen" a la acción no es propiamente la voluntad, sino el entendimiento (Greenberg, 2005, p. 220). De este modo, el principio de razón suficiente es externo a la voluntad, ya que las razones que dirigen la acción provienen de afuera y la voluntad no hace sino acatar una deliberación que se ha producido a nivel intelectual, de modo muy semejante a un silogismo práctico.

16 "Sa position très personnelle (...) se situe à la pointe de l'ontologie de l'essence antérieure à la existence; par suite en tout esprit l'intelligence domine la volonté." 
Entonces, es posible pensar que Dios puede recuperar las deliberaciones de cualquier mente finita en circunstancias futuras o contrafácticas, precisamente porque hay una analogía estructural entre las facultades de Dios y las de la criatura. La libertad sólo se aplica a las mentes y Dios instancia la libertad en el grado más completo: la razón de que quiera $x$ es que su intelecto percibe $x$ como la mejor alternativa - necesidad moral(Davidson, 1998, p. 396). La instanciación que hace cada criatura de la libertad puede llevarla, según los casos, a seguir la obligación o no: la razón de que $a$ quiera $x$ es que su intelecto percibe $x$ como un bien aparente (conforme o no a la necesidad moral). Puesto que Dios puede ver sus deliberaciones, variando incluso los escenarios posibles en que se insertarían, puede saber lo que una criatura elegiría en cada situación ${ }^{17}$. Y esto es así porque en el alma de la libertad se aloja la inteligencia. Por ende, las acciones humanas son solamente predecibles para Dios, pero jamás para una mente finita ${ }^{18}$.

${ }^{17}$ Murray también ha argumentado en esta dirección. A saber: “Debemos reconocer que hay alguna determinación, específicamente una determinación proveniente del intelecto y voluntad del agente, la cual actúa como el determinante del valor de verdad de los condicionales subjuntivos [...] Debemos recordar, no obstante, que lo que aparece como bueno al intelecto está determinado, para Leibniz, por las disposiciones del intelecto. Si el intelecto ha adquirido virtudes percibirá los bienes verdaderos como el bien. Pero si el intelecto ha adquirido vicios, percibirá en efecto los males como bienes y elegirá en forma pecaminosa. Así, una vez más Leibniz apela al punto de vista de que Dios conoce las elecciones conociendo lo que aparece como bueno al intelecto, lo cual, a su vez, está determinado por las disposiciones del intelecto (virtudes o vicios)" (Murray, 1995, p. 89). Justamente, a juicio de Leibniz, los molinistas habrían fallado en no haber reconocido que tales disposiciones son una razón suficiente que cuenta para el conocimiento divino de los futuros contingentes condicionales.

${ }^{18}$ Cabría pensar la posibilidad de hablar en cierto sentido de un "conocimiento no-nomológico," no deducible de legalidad alguna, en tanto Dios no necesitaría servirse de leyes para predecir los cursos de acción 
Por otro lado, esta idea de los contrafácticos entronca con la teoría de la Creación, dado que son los balances contrafácticos los están en la base del cálculo de lo mejor. Por ejemplo: "si Dios creara a Judas, sería cierto que se condenaría". En este sentido, el conocimiento de los contrafácticos depende del conocimiento que Dios tiene de sus decretos hipotéticos. A saber:

Incluso las proposiciones que son objeto de la ciencia media suponen un decreto de Dios, en un modo posible o hipotético ${ }^{19}$ (Grua, 1948, p. 357).

Sin entrar en la cuestión de la identidad transmundana o las contrapartes semejantes, una manera de interpretar el conocimiento de los contrafácticos sería la siguiente: Dios determina el valor de verdad de un condicional contrafáctico (CCF) por la elección hipotética de un mundo posible (MP) en el cual el antecedente del CFF es verdadero (Griffin, 1999, p. 330). Es decir, que Dios podría saber qué cursos de acción seguiría Judas en

del hombre, más allá de las reglas deliberativas que pudieran estar implicadas en cada mente en particular. Esto precisamente justificaría la impredicibilidad de los hombres al pretender tomar por objeto las acciones libres. Así como del conocimiento de las leyes físicas, cualquier mente (finita y con más razón divina) podría predecir las consecuencias observacionales que se siguen de allí (por ejemplo, la caída libre de una piedra, asumiendo que la ley de gravedad no hubiera sido suspendida por un milagro), la ausencia de leyes universales hace que los pensamientos del agente no se vean determinados por causas eficientes, de modo tal que cualquier mente estaría en capacidad de desviar el curso de sus representaciones. He aquí el sentido del célebre -y problemáticopasaje de De natura veritatis, contingentiae et indifferentiae atque de libertate et praedeterminatione (1685-1686?), donde Leibniz comparó la libre acción (por no estar atada a leyes subalternas determinadas del universo) con una suerte de "milagro privado" que interrumpiría el curso de la causalidad eficiente sobre la voluntad (A VI 4, p. 1519).

${ }^{19}$ Extraits de Twisse (hacia 1695): "Itaque etiam propositiones quae sunt objecta scientiae mediae suponunt decretum Dei per modum possibilis seu hypotheseos". 
circunstancias contrafácticas, mirando a aquél MP que satisface la verdad del antecedente ("Si Judas se abstuviera de traicionar a JC, entonces...). Pero ¿cómo saber qué mundo elegiría Dios? Probablemente haya una cuota de temeridad en el intento de dar una respuesta.

Griffin, por su parte, se vale de la imagen de la pirámide sin base, presente en el último parágrafo de Teodicea (GP VI, p. 364), para ofrecer una interpretación basada en la jerarquía de los MP. En la pirámide, nuestro mundo ocupa la cima y todos los demás están ubicados según un orden decreciente de perfección. Entonces conjetura que Dios podría conocer el valor de verdad de un CCF bajando su mirada hasta dar con aquel puro posible donde se cumple la verdad del antecedente. Tal MP sería el mejor de entre aquellos MP en los cuales el antecedente del condicional es verdadero, es decir, sería el mundo que Dios habría admitido a la existencia en caso de querer satisfacer la verdad del antecedente en cuestión. Por lo tanto, la teoría del conocimiento divino de los CCF, dependería de las dos facultades de Dios (entendimiento y voluntad). A saber:

A través de su intelecto, Dios conoce lo que sucede en varios MP y qué relaciones de similitud y optimalidad relativa hay entre estos mundos. Estas cosas descansan fuera del alcance de su voluntad. No obstante, su conocimiento de los contrafácticos depende también de sus «primeros decretos libres» para actuar siempre del modo más perfecto, lo cual determina las elecciones que haría en circunstancias contrafácticas $^{20}$ (Griffin, 1999, p. 332).

\footnotetext{
20 "Through his intellect he knows what happens in various possible worlds and what relations of similarity and relative optimality hold among these worlds. These things lie outside the scope of his will. But, his knowledge of counterfactuals also depends on his "primary free decree" to always act in the most perfect way (DM, 13), which determines the choices he would make in counterfactual circumstances".
} 
Más allá de poder determinar si Leibniz tuvo tal cosa en mente, lo cierto es que tiene su valor como una forma de dar respuesta al problema de los CCF. No obstante, la interpretación de Griffin reclamaría también la tesis compatibilista, dado que es la "libertad ideal" de las criaturas (o contrapartes posibles) la que permite situar la visión divina en el mejor puro posible donde se cumpliría la verdad del antecedente. En otras palabras, Dios puede descender por la pirámide sin base hasta dar con los cursos de acción implicados por cierto CFF, porque en la mente de las contrapartes posibles operan razones (suficientes en el seno de la legalidad hipotética de ese mundo) que, al ponderar los escenarios que se le ofrecen, la llevarían a determinarse en cierta dirección. Ahora bien, si tales cursos de acción servirían lícitamente para pensar a "nuestro Judas," sin tener que emparchar buena parte de la legalidad de nuestro mundo, remite al problema de la identidad transmundana y de cómo se cubrirían los agujeros producidos.

\section{Bibliografia}

ANGELELLI, I. "Foreknowledge, bivalence, freedom." In: BERNHARD, P.; PECKHAUS, V. (Hrsg.). Methodisches Denken im Kontext. Paderborn: Mentis, 2008, p. 43-53.

CARLIN, L. "Leibniz on Conatus, causation, and Freedom." In: Pacific Philosophical Quarterly, v. 85, n. 4, p. 365-379, Dic. 2004.

DAVIDSON, J. "Imitators of God: Leibniz on Human Freedom." In: Journal of the History of Philosophy, v. 36, n. 3, p. 387-411, 1998.

GREENBERG, S. “Leibniz Against Molinism. Freedom, Indifference, and the Nature of the Will." In: RUTHERFORD, D.; COVER, J. A. (eds.). Leibniz: Nature and Freedom. United Kingdom: Oxford University Press, 2005, p. 217-233. 
GRIFFIN, M. V. "Leibniz on God's Knowledge of Counterfactuals." In: The Philosophical Review, v. 108, n. 3, p. 317-343, Jul. 1999.

GRUA, G. Jurisprudence universelle et Théodicée selon Leibniz. Paris: Presses Universitaires de France, 1953.

LAGERLUND, H.; MYRDAL, P. "Possible Wolds and the Nature of Choice in Leibniz." In: Studia Leibnitiana, Band XXXVIII/ XXXIX, Heft 2, Stuttgart: Franz Steiner Verlag, 2006/2007, p. 156-176.

LEIBNIZ, G. W. 1875-1890. Philosophische Schriften, vols. 1-7, editado por C. I. Gerhardt. Berlin (repr. by Georg Olms Verlag, Hildesheim/New York. 1978). Citado como GP seguido por volumen y número de página.

LEIBNIZ, G. W. Sämtliche Schriften und Briefe, editado por la Academia Alemana de Ciencias en Berlín, desde 1923. Citado como A, seguido por serie, volumen y número de página.

LEIBNIZ, G. W. Textes inédites, vols. 1-2, publiés et annotés par G. Grua. Paris: Presses Universitaires de France, 1948.

MURRAY, M. J. "Leibniz on Divine Foreknowledge of Future Contingents and Human Freedom". In: Philosophy and Phenomenological Research, v. 55, n. 1, p. 75-108, Mar. 1995. 